\title{
Um mito português que é afinal de todo o mundo
}

\section{Samuel Silva}
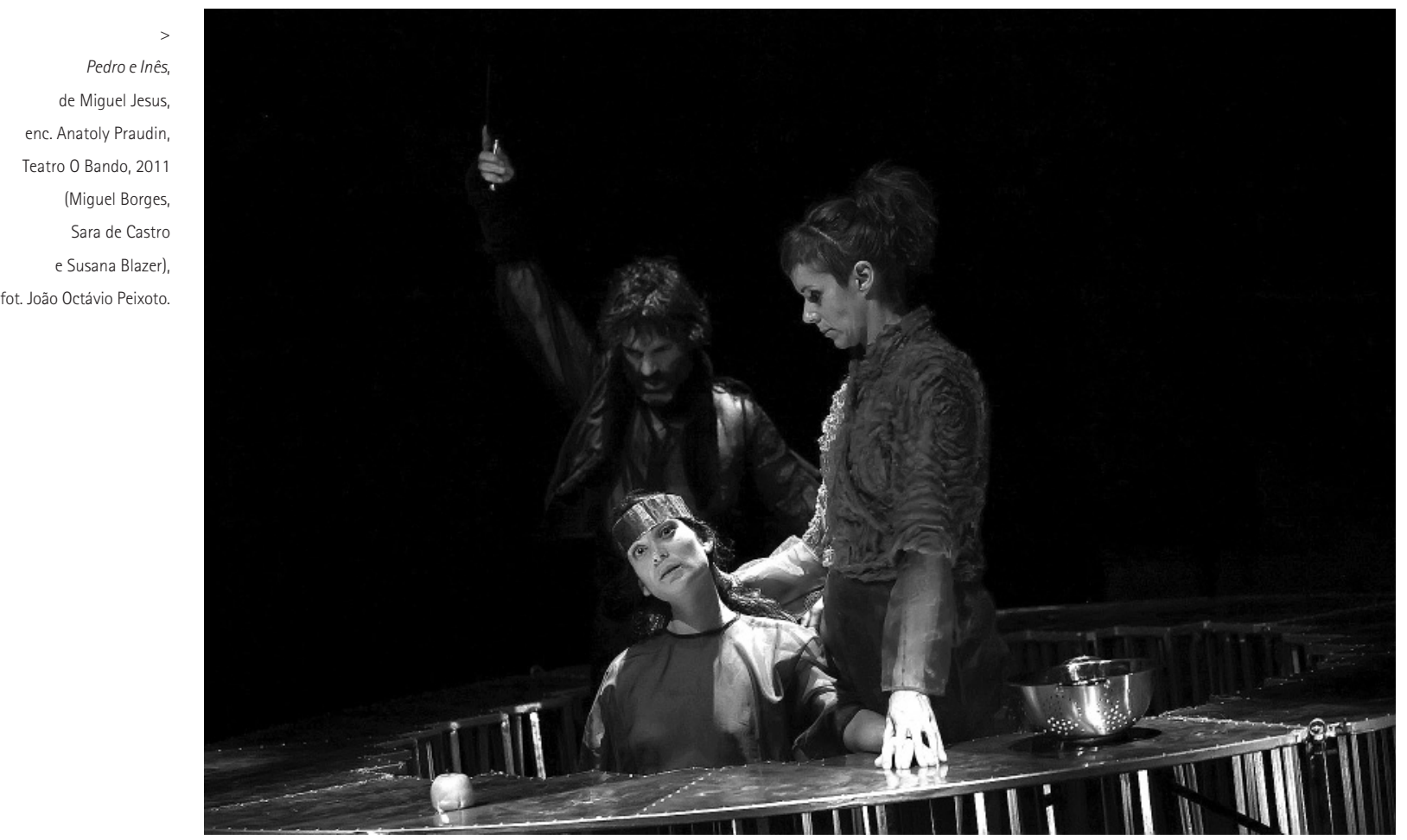

Titulo: Pedro e Inês [Inês morre, 2010]. Autor: Miguel Jesus. Encenação: Anatoly Praudin. Coordenação artística: João Brites. Composição musical: Jorge Salgueiro. Espaço cénico: Rui Francisco. Figurinos e adereços: Clara Bento. Desenho de luz: João Cachulo. Video: Artica. Apoio à dramaturgia: Odette Bereska. Assistência à direcção artistica: João Neca. Interpretação: Estêvão Antunes, Helena Afonso, Horácio Manuel, Ivo Alexandre, Miguel Borges, Sara de Castro e Susana Blazer. Produção: Teatro O Bando, CCB / Centro Cultural Vila Flor / Centro Cultural e de Congressos das Caldas da Rainha / Teatro Municipal de Bragança / Teatro de Vila Real / Cine-Teatro de Estarreja / Centro de Artes de Sines / Teatro Municipal da Guarda e Teatro Virginia. Local e data de ante-estreia: Centro-Cultural Vila Flor, Guimarães, 4 de Março 2011. Local e data de estreia: Centro Cultural e de Congressos, Caldas da Rainha, 11 de Março de 2011.

No Museu Russo de São Petersburgo há um quadro do século XIX que retrata a morte de Inês de Castro, a galega que depois de morta foi rainha de Portugal. Esse facto, que se tornou mito, transformou-se numa das histórias mais vezes contadas e recontadas no pais. E ganhou uma dimensão internacional, europeia sobretudo, porque é feita da massa das grandes narrativas romanescas. Foi esse encantamento romântico que fez a lenda chegar à Rússia, cativando Karl Brulov, que pintou a tragédia real portuguesa em 1834. Tinham passado quase 500 anos sobre o assassinato de Inês e já não seria fácil distinguir entre mito e realidade. Pelo meio, houve um monumento chamado Os Lusíadas, que mudou para sempre a forma de olharmos para esta história. Camões agarrou nela, recontando-a, reimaginando-a, no fundo, condicionando as interpretações futuras que dela vieram a surgir. Tanto é assim que hoje é ainda mais dificil saber o que foi, de facto, o caso do amor proibido e do destino trágico de Pedro e Inês.

Mas o encantamento provocado pelo amor, pela morte e pela vingança que se Ihes seguiu, permanece ainda hoje intacto, e é capaz de envolver portugueses, franceses, ou alemães. Porque há uma tradição europeia de amores trágicos onde o de Pedro e Inês se inscreve, e este não é o único mito em torno de um amor proibido com um final infeliz. Há, pela Europa, outras fábulas em torno da ideia de um amor trágico, maior do que os obstáculos que os homens - ou os deuses - são capazes de colocar. Mas a versão portuguesa, por incluir um rei e uma coroação post mortem, reveste-se de carácter grotesco e apaixonante. 

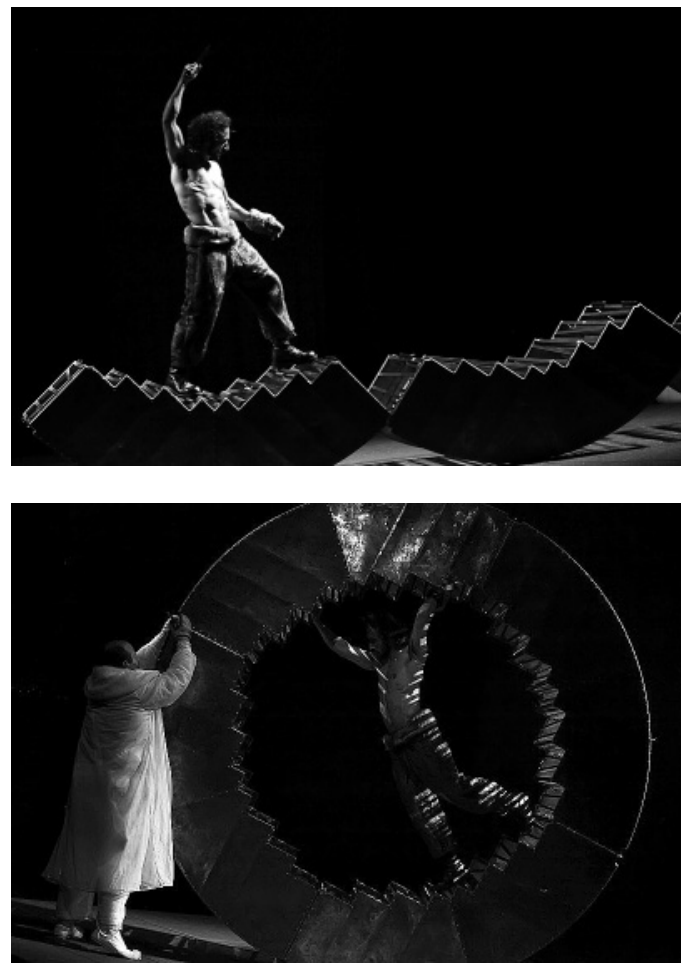

A relação do futuro rei D. Pedro com Inês de Castro é também capaz de cativar os russos. A pintura de Brulov já o tinha mostrado e foi agora a vez de o encenador Anatoly Praudin - director do Teatro Experimental da Casa Báltica, de São Petersburgo - fazer desta história o ponto de partida para a criação artística.

0 resultado é Pedro e Inês, o espectáculo do Teatro 0 Bando, que teve ante-estreia em Março último, no Centro Cultural Vila Flor, em Guimarães. E há alguns pontos de contacto entre as abordagens de Brulov e Praudin. Não estamos perante uma obra romântica, mas o encenador russo abandona progressivamente, ao longo do espectáculo, o puro realismo e abre espaço à metáfora, à imaginação e à fantasmagoria. Arriscamos dizer que de outro modo não podia ser, se tivermos em conta que estamos perante um mito recheado de ambiguidades.

Não estamos - é claro - perante uma pintura, mas este espectáculo define-se, acima de tudo, por uma forte relação visual com o espectador, pela existência de um grande rigor de composição das cenas que absorve alguma inspiração nas artes plásticas. E a obra projectada por Praudin para $\mathrm{O}$ Bando está recheada de pequenos instantes que definem a memória que guardamos de uma criação

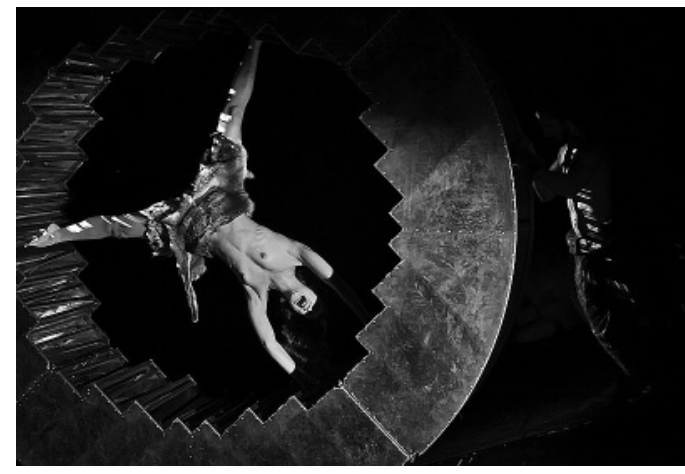

$<>$ $\checkmark$

Pedro e Inês, de Miguel Jesus, enc. Anatoly Praudin, Teatro 0 Bando, 2011 (< Estêvão Antunes; $>$ Susana Blazer e Estêvão Antunes: $\checkmark$ Ivo Alexandre e Estêvão Antunes), fot. João Octávio Peixoto.

artística. Essa apresenta-se como a sua principal riqueza. Para a sua densidade visual muito contribui o trabalho de Rui Francisco na concepção do espaço cénico. No palco - praticamente despido - sobressai um dispositivo redondo e polivalente, capaz de se adaptar às exigências de cada momento do espectáculo e que os actores montam e desmontam com facilidade, sem trairem o ritmo do trabalho cénico. E aquele cilindro de madeira e metal tão depressa pode ser uma sauna real, onde se "cozinham" corpos e traições, como o trono onde Inês de Castro é coroada depois de morta.

Esse é o culminar da loucura de Pedro, cego pela sua vontade de vingança. E no espectáculo d'O Bando é um dos momentos visualmente mais marcante e essencial para justificar a pertinência contemporânea de uma história do século XIV. 0 rei alimenta, venera e dialoga com a mulher inanimada, um momento patético, no duplo sentido que à palavra podemos conferir. 0 amor destrói e esse é o ponto de partida de Pedro e Inês. A máquina de cena, em torno da qual se move toda a encenação, é também capaz de se transformar no mecanismo de tortura medieval onde Inês morre. E a morte dela é outro dos "quadros" que Praudin projecta para sublinhar visualmente a sua intenção de retratar a infâmia humana: pela crueza com que o corpo é exposto, desprotegido e cruelmente diminuído até à sua total inanição. Esta opção altera os dados factuais, uma vez que Inês terá morrido apunhalada e foi assim que Camões a ela se referiu e Brulov a pintou, por exemplo. Mas a forma como morre é aqui secundarizada: ela não morre pela bainha do punhal, mas numa centrifugação violenta, que parece ser mais inspirada em alguns relatos da Inquisição, , ou em outras formas de crueldade da Idade Média.

Esta é, portanto, uma morte "imaginada" porque o que interessa a Praudin e ao Bando é relatar a vileza de um rei, figura máxima de um país, capaz de matar em 


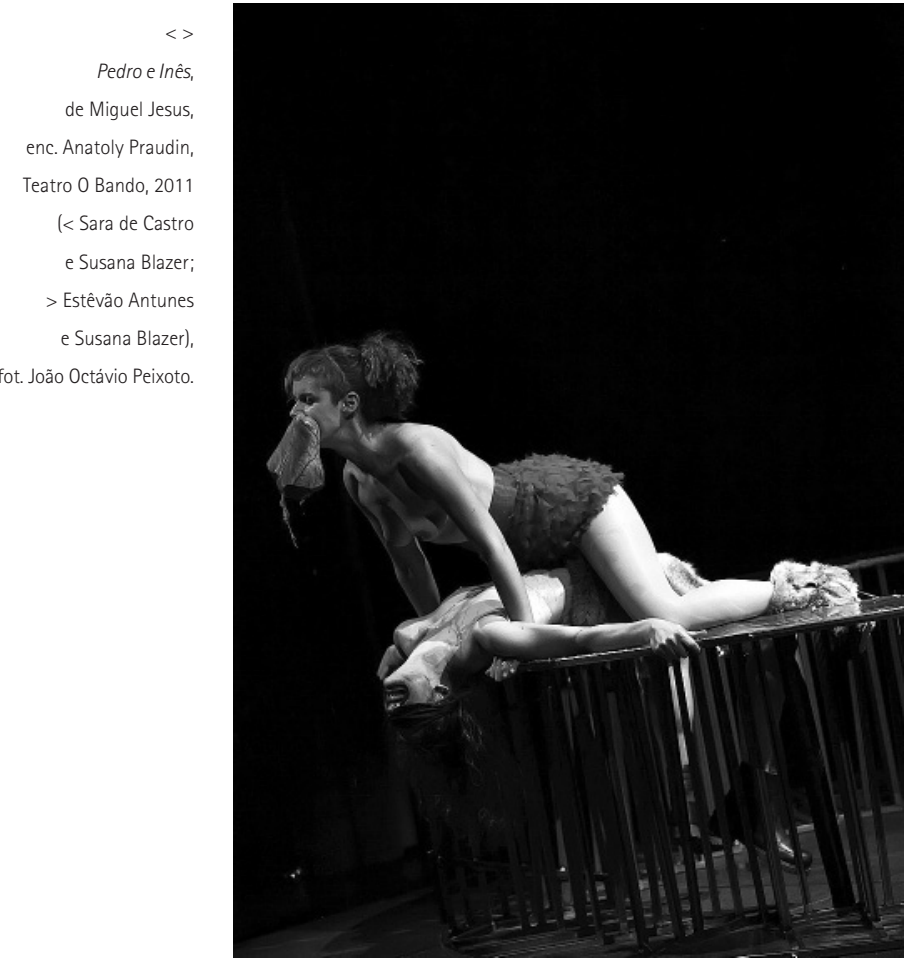

nome do Estado para servir um capricho pessoal, a força destrutiva das relações humanas e as repercussões violentas, de vingança, que daí resultaram. 0 que aqui está em primeiro plano é a psicologia do ser humano, seja ele plebeu ou nobre: animal sempre.

0 espectáculo tem como base o texto Inês morre, que marca uma promissora estreia de Miguel Jesus na dramaturgia. 0 autor está bem documentado no que aos factos históricos diz respeito. Expõe claramente as motivações, consumações e consequências deste amor real. Mas essa aparente força acaba por resultar naquela que é uma das principais fragilidades deste espectáculo, na medida em que, a dada altura, se percebe alguma necessidade de o tornar explicativo. Todavia, esquecemonos disso rapidamente, à medida que somos levados a caminhar, cada vez mais, em direcção a um universo obscuro, onde pouco ou nada é aquilo que parece ser.

A única certeza, que temos, é estarmos perante uma história de agonia. E começamos a perceber a tragédia bem cedo. 0 espectáculo abre com uma canção que soa estranha, quase fantasmagórica, cantada por uma velha - cega, explica o dramaturgo - que há-de servir como uma espécie de coro, ao estilo clássico. "Diz-nos, diz-nos, ó sombra vizinha, quem só depois de ser morta conseguiu ser rainha. Diz-nos, diz-nos, ó história esquecida, quem compra com a morte o que paga com a vida", há-de repetir a personagem várias vezes até à coroação póstuma de Inês.

Já o dissemos: a lenda é portuguesa, mas os seus ingredientes são bem europeus. Contá-la sob a direcção de Praudin - e com a colaboração da alemã Odette Bereska no apoio à dramaturgia - permitiu reforçar a universalidade do mito de Pedro e Inês. Essa canção - a meio caminho entre a lengalenga e o ritual fúnebre incessantemente repetida é cantada num jeito pouco nacional. Tal como a opção tomada para retratar a morte de Inês de Castro, também aqui há uma aproximação à

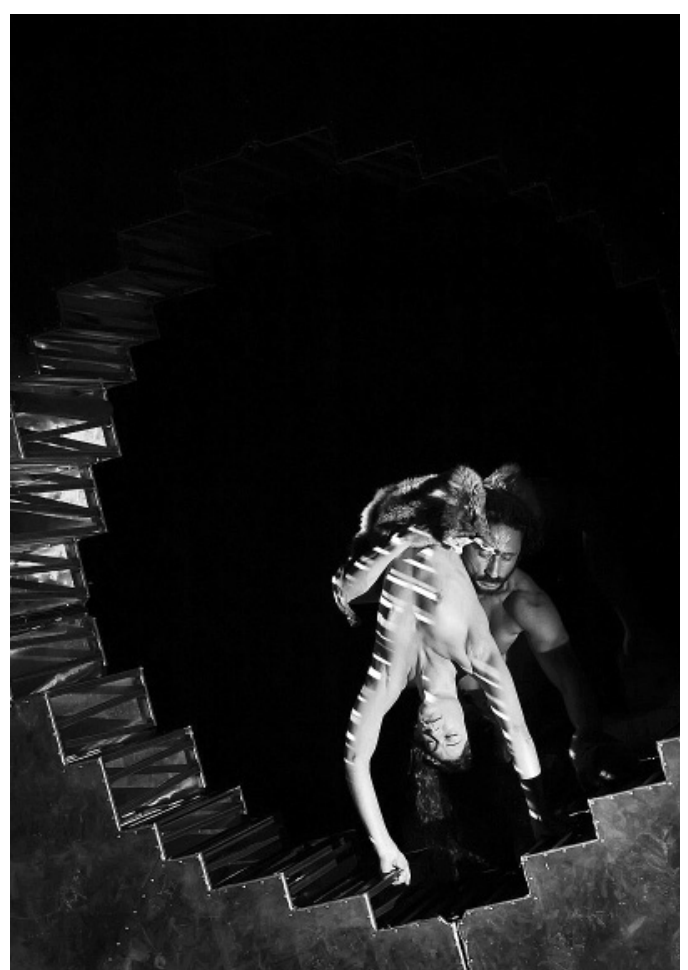

cultura da Europa central. Mas isso resulta bem junto do público português. Aquela musicalidade é-nos estranha e isso reforça a sua força em palco, e há-de, também por isso, acompanhar-nos até ao final do espectáculo. Essa fantasmagoria embala-nos e embala Pedro e Inês, acentuando o que de mais grotesco se esconde nos pormenores do enredo.

Outra das marcas de Pedro e Inês é a presença obsessiva do corpo em cena. Se a Anatoly Praudin e ao Bando interessa retratar a aspereza psicológica e a animalidade do ser humano, a opção por desnudar várias vezes os actores ao longo do espectáculo ajuda-nos a olhar para o que de mais básico neles existe. Desprovidos das roupas que Ihes conferem protecção nas relações que estabelecem enquanto seres sociais, os homens e mulheres desta história são-nos apresentados mais próximos de um "estado de natureza" (se me é permitido o recurso a Rousseau). E, mais uma vez, esta é uma tradição que é mais comum na Europa central e do Leste do que na cultura latina em que nos inserimos. Este não é um amor platónico: é um amor consumado, obsessivo. Um amorcarne. Se o não fosse, não teria os resultados violentos que reconhecemos na crónica e no mito.

Esta opção pelo corpo é também estética e percorre todo o espectáculo, em especial nas cenas visualmente mais marcantes: Inês morre seminua e é assim que o seu carrasco prepara a máquina de morte. É assim também na coreografia entre Inês e Teresa, a sua dama de companhia, que veste por momentos o corpo de Pedro. As duas mulheres ensaiam a consumação carnal do amor. E a carne está mesmo presente, enquanto Teresa e Inês coreografam o desejo sexual que as invade, um coração de animal interpõe-se entre os seus corpos até explodir e esvair-se em sangue. 0 sangue é amor. Também é morte. E Pedro e Inês é, acima de tudo, um espectáculo sobre essa dualidade no que de mais violento ela pode conter. 